\title{
A Cross-sectional Online Survey on Knowledge, Attitude, and Perception of COVID-19 among Ghanaians
}

\section{Ebenezer Akuoko}

Far Eastern Federal University, Russia

Cyril Alando ( $\nabla$ alhandrocyrilnho@gmail.com )

Freelance Public Health Research Scientist, Zuarungu, Upper East, Ghana https://orcid.org/0000-00030725-1307

\section{Research Article}

Keywords: Knowledge, Attitude, Perception, COVID-19, SARS-COV-2, 2019-nCoV, Ghana

Posted Date: September 16th, 2020

DOl: https://doi.org/10.21203/rs.3.rs-74512/v2

License: (c) This work is licensed under a Creative Commons Attribution 4.0 International License. Read Full License 


\section{Abstract}

This study examined knowledge, attitude, and perceptions of COVID-19 among Ghanaians. A crosssectional survey was conducted using Google forms to recruit 503 participants over six weeks. We performed descriptive statistical analysis, and presented results in tables/charts. From the results, $66.4 \%$ of respondents depended on social media for COVID-19 related information, and $59.8 \%$ mostly heard/read about preventive measures in all COVID-19 information heard/read. Knowledge was adequate, but with noticeable gaps. Attitude was generally positive, with $84.1 \%$ willing to accept reintegration of treated COVID-19 patients. Perceptions were healthy, with only $3.8 \%$ perceiving insusceptibility. We conclude that these findings contribute significantly to the literature on COVID-19 in Ghana. We recommend the continuous use of social media by the Government of Ghana and relevant stakeholders for COVID-19 communications, and further research in the general population for evidence based COVID-19 prevention interventions in Ghana.

\section{Introduction}

\section{Background}

Infections from viruses are of public health importance, as they frequently complicate the course of treatment (Eun-Hyung \& Treanor, 2016). Over the years, there have been several viral disease outbreaks with their origins from animals. For instance, the severe acute respiratory syndrome (SARS) outbreak originated from bats of the genus Rhinolophus, and its human emergence is believed to have been facilitated through intermediate hosts in the wet markets of southern China. The H1N1 influenza epidemic arose in North America primarily through the re-assortment of viruses of swine origin (Wang, 2007; Webster, 2004). The various strains of the Ebola virus originated from the blood, secretions, organs, or other bodily fluids of infected animals such as fruit bats, chimpanzees, gorillas, monkeys, forest antelope or porcupine found ill or dead or in the rainforest (WHO, 2020a).

Such outbreaks and pandemics, such as Coronavirus disease, have demonstrated the vulnerability of humans to the threats they pose to us. They have also exposed our inability to predict or prevent such events (Pike, et al., 2010). The outbreak of Coronavirus Disease in 2019 (COVID-19), a disease that occurs due to an infection from a novel coronavirus (2019-nCoV or SARS-COV-2), is yet additional evidence of global human vulnerability to emerging disease outbreaks and zoonotic diseases specifically.

This novel coronavirus is among a family of viruses that may cause various symptoms, such as pneumonia, fever, breathing difficulty, and lung infection (WMHC, 2020). The COVID-19 epidemic broke out in Wuhan, China, in late 2019. By the middle of March 2020, the disease had spread to countries in Asia, Europe, North and South America, Africa and Oceania. In response to a global concern, the World 
Health Organization (WHO) declared COVID-19, a pandemic on 11th March 2020. On 12th March 2020, the European Region was declared the new epicenter of the pandemic away from Wuhan, China, with more than 20,000 cases and approximately 1000 deaths in the region (WHO, 2020b).

Most people infected with the COVID-19 virus experience mild to moderate respiratory illness and recover without requiring special treatment. Older people and those with underlying medical problems such as cardiovascular disease, diabetes, chronic respiratory disease, and cancer are more likely to develop serious illness (WHO, 2020c; Worldometer, 2020).

To control the spread of the disease, the WHO outlined the following protocols to be observed: washing hands frequently with soap, under running water, or using alcohol-based hand-sanitizing gel; maintaining social distance/physical distance of 1 meter (3 feet) or more between persons; avoiding touching of the eyes, nose and mouth; observing respiratory hygiene etiquette (by covering mouth and nose with the bent elbow or tissue when one coughs or sneezes); seeking medical care early when one has a fever, cough and difficulty breathing; and staying informed and following advice given by health-care providers, national and local public health authorities on all the COVID-19 preventive protocols (WHO, 2020b).

Subsequently, countries across the globe took measures to contain the spread of the disease, implementing various levels of restrictions of movement of people. There were also travel restrictions and the closure of academic institutions and other social gatherings. That notwithstanding, several countries recorded daily increases in the disease incidence. Reports on 7th August 2020 showed that the total number of global confirmed cases stood at 19,257,695, out of which 1,011,872 were recorded among 57 African countries, including Ghana (Worldometer, 2020). During the same period, 717,687 COVID-19related deaths were recorded globally, out of which 22,114 were recorded among these 57 African countries, excluding Eritrea and Seychelles (Worldometer, 2020).

On 14th February 2020, Egypt became the first African country to confirm a case of the disease. By 1 April 2020 , forty-two (89\%) out of 47 Member States of the WHO African Region were affected. The most affected countries in the WHO African Region were South Africa (1, 353 cases), Algeria (584 cases), Burkina Faso (261 cases), Senegal (175 cases), Cote d'Ivoire (169 cases), and Ghana (152). Together, these countries accounted for $72 \%$ of the cases reported in the region (WHO, 2020d). 
In Ghana, the first two cases of COVID-19 were recorded on 15th March 2020. By 7th August 2020, the number of confirmed cases stood at 39,642, with 36,284 recoveries and 199 deaths (Ghana Health Service, 2020a; Worldometer, 2020). In response to control measures, the President of Ghana, acting on the Imposition of Restrictions Act, 2020 (Act 1012), imposed restrictions on the movement of people (Ghana Health Service, 2020b).

Viral infections pose ever-increasing challenges to public health and safety. Their high mutation rates enable viruses to easily develop drug resistance towards conventional therapeutics, which mainly inhibit essential viral proteins. This increases the levels of risk and severity associated with the outbreak of a novel viral disease, since most of the current antiviral drugs are virus specific formulations (Durmus \& Ülgen, 2017).

In the anxious wait for the development of more rapid and effective therapeutics and vaccines to combat the disease, the fight remains that of a collaborative effort. However, in the absence of a known vaccine, effective control of the disease rests largely with primary preventive measures that require good knowledge, attitude, and perceptions about the disease among the population, the reason why this study sought to examine the knowledge, attitude and perception of the disease among Ghanaians. The findings in this study will thus serve as evidence for policy adjustments for the prevention and control of COVID-19 in Ghana.

\section{Materials And Methods}

\section{Study design}

A cross-sectional study was conducted among Ghanaian internet users. Ghanaians on various social media platforms were invited to complete a self-administered questionnaire through a link.

\section{Sampling}

A total of 503 respondents completed the self-administered online questionnaire, which was designed using Google forms. A minimum required sample size of 385 was calculated using Raosoft, an online sample size calculator (Raosoft Inc., 2004), with the following assumptions: a 5\% margin of error, $95 \%$ confidence interval, $50 \%$ response distribution, and $25,000,000$ population of Ghanaians actively online.

\section{Inclusion and exclusion criteria}


The study was delimited to only Ghanaians who were residents in Ghana and online at the time of the study. The form was then designed to deny access to a respondent who answered "No" to the compulsory question of whether they were Ghanaians who were currently living in Ghana.

\section{Study Instrument}

The questionnaire asked questions on knowledge, including how they received information on COVID-19, which types of information were most commonly known to them, and how frequently they were exposed to education on preventive measures of the disease. Their attitudes were assessed by asking question on which of the impacts of COVID-19 were of most concern to them, how they related, or would relate with treated COVID-19 patients, and how frequently they observed the preventive measures of the pandemic, as outlined by the WHO. Their perceptions were then assessed by obtaining responses to their perceived susceptibility, disease severity, and efficacy of medical care given to people with COVID-19. They were also asked self-efficacy questions such as how they perceived their abilities to observe the preventive measures as outlined by the WHO.

\section{Data collection}

An invitation link to participate in the study was sent to participants through Emails, WhatsAPP, and Facebook, which directed them to the questionnaire on Google forms. The data were collected from April 27, 2020 to June 15, 2020. The data collection instrument was pretested on five (5) Ghanaian students who were studying outside Ghana at the time of data collection from $23^{\text {rd }}$ April to $26^{\text {th }}$ April 2020, after which necessary corrections were made.

\section{Data analysis}

The Statistical Package for Social Sciences (IBM SPSS) version 20.0 was used for data cleaning and analysis after the data were downloaded from the Google server. Microsoft Excel (MS-Excel 2010) was employed to generate the charts and tables. The data were analysed descriptively with the aim of describing the study variables and their distributions through univariate and bivariate analyses, result of which are presented in frequency tables and charts.

\section{Ethical consideration}

This study was carried out in accordance with the 1964 Helsinki declaration and its later amendments on research ethics. The study participants were adequately informed about the study and assured of 
confidentiality and anonymity. Their autonomy was guaranteed since this was an online study using a self-administered questionnaire. Consent was also obtained before access to the survey instrument was granted. Study participants were not required to submit their email addresses before having access to the questionnaires. However, participants who were interested in knowing the study results were asked to voluntarily submit their email addresses. These addresses were separated from their responses to anonymise and de-identify the data and were secured with the researchers for the sole purpose of communicating the study findings.

\section{Results}

\section{Demographic Characteristics of Respondents}

The results in Table 1 show the demographic characteristics of the 503 study respondents. The majority, 241 (47.9\%) of respondents were adults aged 25 to 54 years, with the youth, aged 15 to 24 years, being the second highest 238 (47.3\%) age group in this study. There were 350 (69.6\%) males and $153(30.4 \%)$ females. The majority of the respondents had had tertiary education, 375 (74.5\%); were Christians, 392 (77.9\%); and had never been married, 348 (69.2\%). There was, however, no observation for respondents aged less than 15 years.

$\ll$ insert Table 1 >

\section{Knowledge of Respondents on COVID-19}

Figure 1 shows that knowledge about COVID-19 among respondents was generally good, and exposure to information, education and communication (IEC) messages on COVID-19 and its prevention was nearly universal.

The majority of respondents indicated that they "often" or "very often" heard or read information concerning the use of alcohol-based hand sanitizing gel, 460 (91.4\%); and frequent washing of hands with soap under running water, 421 (83.7\%). Overall, between $33.6 \%$ and $42.5 \%$ of respondents reported that they were either "often" or "Very often" exposed to each of the recommended COVID-19 infection prevention protocols. 
It was also important to know respondents' sources, providers, and types of COVID-19 IEC messages frequently heard. This study discovered that the majority, $334(66.4 \%)$ of respondents, were informed about the disease through social media channels. Correspondingly, the most heard/read about IEC messages that were communicated to respondents were on preventive measures, where 301 (59.8\%) of respondents confirmed their exposure to these messages.

However, families were the least reported source of information on the disease, only ahead of newspapers that recorded no response (See Table 2).

\section{$<<$ insert Table 2>>}

\section{Attitude of respondents towards COVID-19}

Table 3 shows responses to a series of questions on what concerns respondents most about the pandemic. Personal infection was of most concern to a majority, $141(28.0 \%)$, of respondents. Global infection, 108 (21.5\%), and local infection, 106 (21.1\%), equally saw significant proportions of the respondents being concerned about them.

Relative to respondents' willingness to accept the reintegration of treated COVID-19 patients into their communities (as a measure of testing their tendency to stigmatise), nearly half, 251 (49.9\%), of the respondents were highly willing to accept reintegration of treated patients into their communities. Nonetheless, a significant proportion $80(15.9 \%)$ of respondents indicated that they were less willing to accept the reintegration of treated COVID-19 patients into their vicinities (see Table 3 ).

\section{$<<$ insert Table 3 >}

To further understand respondents' attitudes towards the pandemic, we asked questions relating to their adherence to the infection prevention protocols. Figure 2 is a representation of responses to these further attitude questions. Some 188 (37.4\%) respondents washed their hands very often, while 236 (46.9\%) washed their hands only that often. Between $13.0 \%$ and $37.4 \%$ of respondents adhered to the infection 
prevention protocols very often, while another $31.0 \%$ to $48.7 \%$ only adhered to them often. Only a minority $(1.0 \%-6.0 \%)$ of respondents did not show a positive attitude by indicating that they did not adhere to the recommendation to observe the protocols (see Figure 2).

\section{$<$ insert Figure 2>>}

\section{Perceptions of respondents on COVID-19}

There were mixed perceptions among study participants. For instance, although up to 241 (47.9\%) respondents rated their susceptibility as high, another 168 (33.4\%) thought they were only moderately susceptible. Similarly, a majority, 230 (45.7\%), perceived the disease as moderately severe, while another $93(18.5 \%)$ thought the treatment protocols used in Ghana were less efficacious for the management of the disease (see Figure 3).

$<<$ insert Figure 3>>

The results further showed that whereas $141(28.0 \%)$ of respondents perceived that they were highly able to frequently wash their hands, $276(54.9 \%)$ others thought they were only able to wash their hands. Conversely, $86(17.1 \%)$ of them perceived that they were less, or not at all, able to frequently wash their hands with soap under running water. The majority of them were less able to avoid touching their face, 275 (54.7\%), and observed respiratory hygiene, 224 (44.5\%). Additionally, a significant proportion, 197 $(39.2 \%)$ respondents perceived that they would be less or not at all able to seek early medical care if they suspected they were infected (see Table 4).

\section{< insert Table 4»>}

\section{Discussion}

\section{Knowledge of Respondents on COVID-19}

In the fight against the Coronavirus Pandemic, one key measure several governments, the WHO, and other stakeholders have adopted is the periodic sharing of information about updates on preventive protocols, new cases, new deaths and new recoveries. The study results demonstrate that $66.4 \%$ of the respondents 
depended on social media for most of the information they received about COVID-19 in Ghana. Similar to the results obtained by an earlier study by Abdelhafiz et al. (2020) and another that was conducted among South Africans, Kenyans and Nigerians and published online, the use of social media was a predominant channel over more traditional channels such as TV, Radio, Newspapers, Family and Friends (Abdelhafiz, 2020; GeoPoll, 2020). Quite expectedly, the use of newspapers was not recorded by any respondent as their most used channel of information. This may be due to the restrictions imposed by the government on the operations of businesses and movement of people. This is because, in Ghana, people usually buy their newspapers while they are out of the houses, as it is uncommon to have individual newspaper subscriptions where these papers are regularly delivered at home. The rest who would usually benefit from their employers' subscription will also miss out due to the restrictions.

One thing that became of great concern in this period of the pandemic was the dissemination of inaccurate and fake news about the virus. With the growing access to and use of the internet and social media, health professionals and scientists are able to have direct interactions with people by sharing accurate information on awareness, safety measures, and emerging research (Alejandro, 2020). On the other hand, several people spread sensational rumors, misinformation, and disinformation, making the fight against the pandemic difficult (Jayaseelan, Brindha, \& Waran, 2020). While it is encouraging that up to $77.9 \%$ of the respondents involved in this survey received most of the information they had about the disease from health professionals, it is worrying that others may not be receiving the accurate information needed for the effective fight against the pandemic. To control the spread of an infectious disease such as COVID-19, epidemiologists must have an understanding of the epidemiological triad of the disease, which is the interplay between the agent, host and environment (Johnson-Walker \& Kaneene, 2018). This provides further information on preventive measures, risk factors, treatment methods, nature of the virus, and its mode of transmission. From the study results, there appears to be much focus on preventive measures of the virus by providers of information, as $60 \%$ of the respondents established it as the most common information they had received. This, the researchers believe to be appropriate for public health and safety regarding COVID-19 prevention and control among the general population.

As a measure to control the spread of the disease, the World Health Organization on12th March 2020 outlined the COVID-19 preventive protocols to be observed (WHO 2020b). Subsequently, a series of public education on the pandemic has focused on educating people about these safety measures in Ghana (Agyeman-Manu, 2020). This information appears to have circulated well in Ghana. This is because, from the study results, except for the avoidance of touching of eyes, nose, and mouth, all the other preventive protocols as outlined by the WHO were very often and often read or heard about by over $70.0 \%$ of the respondents in each case. The most commonly circulated public education was about the frequent use of alcohol-based hand sanitizing gel, followed by the frequent washing of hands with soap under running water. 


\section{Attitudes of Respondents towards COVID-19}

The respondents had varying views about what concerns them most about the impact of the pandemic. For the top three concerns, $70.6 \%$ of respondents were more concerned about personal infections, global infections, and local infections. While there have been widespread outcries about the impact of COVID-19 on economies, only $7.0 \%$ of the respondents considered that to be of more concern. A similar study conducted among South Africa, Kenyans and Nigerians and published online also found global and personal infections as among the first three most common impacts people were concerned with (GeoPoll, 2020). However, unlike in this current study, economic impact was part of the first three concerns in that earlier study. One thing that has been of great concern is the stigmatization against people with COVID-19 and their families, even after they have been declared treated by health officials. There have been several such reports of discrimination in Ghana (Awuni, 2020; Citi Newsroom, 2020a, 2020b; Noi, 2020). Contrary to such reports, the results from this study show that $84.1 \%$ of the respondents indicated that they were highly willing or willing to accept the integration of COVID-19-treated patients into their communities. In fact, approximately half $(49.4 \%)$ of the respondents specifically indicated that they were highly willing to accept reintegration of treated patients. Nonetheless, even though none of the respondents showed sharp tendencies to stigmatise patients by not indicating unwillingness to accept reintegration of treated patients, a significant (15.9\%) proportion of them were less willing. This was an indication that there is a real and potential threat of stigmatizing attitudes among the study population. It is, however, assumed that if our study participants who had some level of formal education and were more inclined to be more informed were exhibiting unfavorable attitudes towards patients, the situation could be worse among the general Ghanaian population.

From the study results, the majority of respondents demonstrated an overall impressive attitude towards the observation of the preventive measures as outlined by the WHO. In fact, $84.3 \%$ of respondents reported frequently washing hands with soap under running water, $77.1 \%$ frequently used alcohol-based hand-sanitizing gels and so on. However, quiet not surprisingly, more than half of the study participants could not as often avoid touching their eyes, nose, and mouth as possible.

\section{Perceptions of respondents on COVID-19}

People perceive differently their susceptibility to getting a particular disease, how severe the disease is, and how efficacious treatments given to people with the disease are. This was true in this study, as the 
results show that different respondents expressed that they were highly susceptible, moderately susceptible, less susceptible, or not susceptible at all. It is impressive to recognise that only $3.8 \%$ of the study participants indicated that they were not susceptible at all. Evidence exists that people who perceive that they are susceptible to a particular disease are more likely to take preventive actions than those who do not feel susceptible (Jones, Jensen, Scherr, Brown, Christy, \& Weaver, 2015; Joseph, Burke, Tuason, Barker, \& Pasick, 2009). Indeed, according to the WHO, the virus infects people of all ages, although older people and people with underlying medical conditions are at higher risks of disease severity. The WHO advises that all must protect themselves from COVID-19 to protect others (WHO, 2020e).

Similarly, respondents expressed different views about how they perceive the severity of the disease. While almost all the study participants perceived some degree of severity of the disease, just $0.8 \%$ felt that the disease was not severe. This shows a positive perception, as people who perceive that a particular disease is severe are more likely to adopt preventive measures against the disease (Jones, Jensen, Scherr, Brown, Christy, \& Weaver, 2015; Joseph, Burke, Tuason, Barker, \& Pasick, 2009). The efficacy of medical care given to people with COVID-19 was also expressed in different terms by the study respondents. Again, just 1.4\% of them believed that the medical care given for COVID-19 was not efficacious.

The ability of people to perform various preventive measures against COVID-19, as presented by the WHO, is an important part of our collective fight. The study results show that $82.9 \%$ of the respondents indicated that they were either highly able or able to frequently wash their hands with soap under running water. However, the results on the ability of participants to frequently use alcohol-based hand-sanitizing gel; to observe social distancing; seek medical care early, when they experience a fever, cough and difficulty breathing; and to stay informed and following advice on COVID-19 were not satisfactory. What was more disturbing, although not very surprising, was that only $55.5 \%$ of study participants were highly able or simply able to frequently observe respiratory hygiene, and less than half (45.3\%) reported that they were highly able or only able to avoid touching their eyes, nose, and mouth frequently.

\section{Limitation}

Because this was an online survey in design, the study faced a limitation where people who were less formally educated and could not complete the self-administered questionnaire and/or were not online at the time of data collection might have been excluded but whose inclusion could have influenced the 
results in this study. This requires cautious interpretation and limits generalizability. It is also reasonable to suspect that because this was a self-administered questionnaire, it might have led to some response bias. However, due to the large sample size, design of the questionnaire, and adherence to ethical procedures, including the assurance of anonymity and confidentiality of data, the researchers believe that the results in this study have not been biased.

\section{Conclusions}

This article concludes that it has made a significant contribution to the body of science that can be dependent on for evidence-based policy formulation for COVID-19 in Ghana. It also resolves that the use of social media platforms by the government and other stakeholders for COVID-19 information, education, and communication is commendable and must be continued, especially for the benefit of the youth and social media active population in Ghana. There is an impressive level of positive attitudes towards the practice of the various preventive measures as outlined by the WHO among the study participants. Although the majority of Ghanaians do not deny their susceptibility to getting the disease, a significant proportion perceives COVID-19 not to be severe. However, because the majority of respondents indicated that they were unable to avoid touching their faces, we recommend that Ghanaians should develop the habit of using face shields to help prevent how often they would have directly touch their faces and possibly pass on an infection. Finally, there is an urgent need for anti-stigma communications to mitigate its negative effects in Ghana.

\section{Abbreviations}

$\begin{array}{llll}\text { COPD } & - & - & \text { chronic obstructive pulmonary disease } \\ \text { COVID-19 } & - & - & \text { Coronavirus Disease, } 2019 \\ \text { H1N1 } & - & - & \text { An influenza virus strain } \\ \text { IEC } & - & - & \text { Information, Education and Communication } \\ \text { SARS } & - & - & \text { Severe Acute Respiratory Syndrome } \\ \text { SHS } & - & - & \text { Senior High School } \\ \text { SPSS } & - & - & \text { Statistical Package for Social Scientists } \\ \text { SSS } & - & - & \text { Senior Secondary School } \\ \text { WHO } & - & - & \text { World Health Organization }\end{array}$

\section{Declarations}




\section{Data Availability}

The data underlying the findings of this study are available on reasonable request to the first author (akuokoebenezer@gmail.com)

\section{Ethical Approval}

N/A

According to the GHS-ERC guidelines/standard operating procedures; Research studies that are of minimal risk, such as survey procedures, interview procedures, or observation of public behaviour, are exempt from ethical review/clearance. EXCEPT, if information is obtained in a manner that subjects can be identified; and any disclosure of human subjects' responses outside the research could reasonably place subjects at risk of harm.

Our study, which was online and self-administered, posed no harm to our subjects other than the psychological burden of responding to the questions, which is not different from their daily psychological requirements in life. Our study on Knowledge, Attitude and Perception is a survey observing public behaviour, which can be likened to a market survey, and is thus exempt for ethical clearance as provided for by the GHS - ERC.

\section{Consent}

Informed consent was obtained from all participants for this study.

\section{Conflicts of Interest}

The authors declare that there is no conflict of interest regarding the main research, authorship and publication of this paper.

\section{Authors' Contribution}


EA conceived the main study, and CA contributed to its design. EA and CA contributed to data collection, analysis, or interpretation. EA drafted the manuscript, and both authors critically revised the manuscript for intellectual suitability. Both authors approved the revised manuscript and accept responsibility for all aspects of the work and its content.

\section{Funding Statement}

There was no funding for this study.

\section{Acknowledgments}

The authors are grateful to Mr Benjamin C. N. Spears and Mr Okyere Kwame Brobbey for their many suggestions during the study and manuscript preparation. We also acknowledge the efforts of all those who helped us by sharing the link to the survey instrument, as well as our respondents. We thank you.

\section{References}

Abdelhafiz, A. S. (2020). Knowledge, Perceptions, and Attitude of Egyptians towards the Novel Coronavirus Disease (COVID-19). Journal of Community Health, 45(5):881- 890. https://doi.org/10.1007/s10900-020-00827-7

Agyeman-Manu, K. (2020). For Immediate Release: Ghana confirms two cases of COVID-19. Press Release. [Online] Avaliable:

https://ghanahealthservice.org/covid19/downloads/covid_19_first_confirmed_GH.pdf 2020)

Alejandro, L. G. (2020). Coronavirus Researchers Are Using High-Tech Methods to Predict Where the Virus Might Go Next. Times. [Online] Avaliable: https://time.com/5780683/coronavirus-ai/ (June 18, 2020)
Awuni, F. (2020). NCCE moves to curb COVID-19 stigmatisation in Upper East. Avaliable: https://citinewsroom.com/2020/05/ncce-moves-to-curb-covid-19 east/ (March 31, 2020)
(March 17,

Citi Newsroom. (2020a). COVID-19 Private Sector Fund launches anti-stigmatization campaign. [Online] Avaliable: https://citinewsroom.com/2020/06/covid-19-private- sector-fund-launches-anti- 
stigmatization-campaign/ (June 15, 2020)

Citi Newsroom. (2020b). Barry Callebaut MD campaigns against stigmatization of persons infected with COVID-19. [Online] Avaliable: https://citinewsroom.com/2020/04/barry-callebaut-mdcampaigns-against -stigmatization-of-persons-infected-with-covid-19/ (June 12, 2020)

Durmu,s, S., \& Ülgen, K. Ö. (2017). Comparative interactomics for virus-human protein-protein interactions: DNA viruses versus RNA viruses. FEBS Open Bio, 7(1):96-107. https://doi.org/10.1002/2211-5463.12167

Eun-Hyung, L. F., \& Treanor, J. J. (2016). Infectious Diseases of the Lungs 32 Viral Infections. Murray and Nadel's Textbook of Respiratory Medicine, 2-Volume Set. https://doi.org/10.1016/B978-1-4557-33835.00032-4

GeoPoll. (2020). Coronavirus in Africa: A study of the knowledge and perceptions of coronavirus (COVID19 ) in South Africa, Kenya, and Nigeria. [Online] Avaliable:

https://reliefweb.int/sites/reliefweb.int/files/resources/GeoPoll-COVID19-Infographic. pdf (March $23,2020)$

Ghana Health Service. (2020a). COVID-19: Ghana's outbreak response, management, and updates. Situation update, COVID-19 outbreak in Ghana. [Online] Avaliable: https://www.ghanahealthservice.org/covid19/\# (May 27, 2020)

Ghana Health Service. (2020b). COVID 19; Ghana's outbreak response management updates. Cancellations/Suspensions/Closures. [Online] Avaliable:

https://www.ghanahealthservice.org/covid19/cancelled.php (May 27, 2020)

Jayaseelan, R., Brindha, D., \& Waran, K. (2020). Social Media Reigned by Information or Misinformation About COVID-19: A Phenomenological Study. SSRN Electronic Journal. https://dx.doi.org/10.2139/ssrn.3596058

Johnson-Walker, Y. J., \& Kaneene, J. B. (2018). Beyond One Health. From Recognition to Results. Epidemiology: Science as a Tool to Inform One Health Policy. 3-30. Wiley Online Library. [Online] Avaliable: https://onlinelibrary.wiley.com/doi/10.1002/9781119194521.ch1

(March 12, 2020)

Jones, C. L., Jensen, J. D., Scherr, C. L., Brown, N. R., Christy, K., \& Weaver, J. (2015). The Health Belief Model as an Explanatory Framework in Communication Research: Exploring Parallel, Serial, and Moderated Mediation. Health Communication, $\quad 30(6): 566-576$. https://doi.org/10.1080/10410236.2013.873363

Joseph, G., Burke, N. J., Tuason, N., Barker, J. C., \& Pasick, R. J. (2009). Perceived Susceptibility to Illness and Perceived Benefits of Preventive Care: An

Exploration of Behavioral Theory Constructs 
in a Transcultural Context. Health Education \& Behavior, 36(5suppl):1-19. https://doi.org/10.1177/1090198109338915

Noi, S. M. (2020). Samuel Mensah Noi writes: Stigma in the era of COVID-19. Opinion. [Online] Avaliable: https://citinewsroom.com/2020/05/samuel-mensah-noi-writes -stigma-in-the-era-ofcovid-19/ (June 2, 2020)

Pike, B. L., et al. (2010). The Origin and Prevention of Pandemics. Clin. Infect. Dis, 50(12):1636-1640. http://doi.org/10.1086/652860

Raosoft Inc. (2004). Sample Size Calculator by Raosoft Inc. Sample Size Calculation. [Online] Avaliable: http://www.raosoft.com/samplesize.html (March 25, 2020)

Wang, L. F. (2007). Bats, civets and the emergence of SARS. Curr Top. Microbiol Immunol, 315:325344. http://doi.org/10.1007/978-3-540-70962-6_13

Webster, R. G. (2004). Wet markets-a continuing source of severe acute respiratory syndrome and influenza? Lancet, 363(9404):234-236. https://doi.org/10.1016/S01406736(03)15329-9

WHO. (2020a). Fact sheet: Ebola virus disease. [Online] Avaliable: https://www.who.int/news$\mathrm{room} /$ fact-sheets/detail/ebola-virus-disease (April 22, 2020)

WHO. (2020b). WHO announces COVID-19 outbreak a pandemic. Coronavirus Disease COVID-19 outbreak. [Online] Avaliable: http://www.euro.who.int/en/health $\quad$-topics/healthemergencies/coronavirus-covid-19/news/news/2020/3/who-announces -covid-19-outbreak-apandemic (April 15, 2020)

WHO. (2020c). A second COVID-19 case is confirmed in Africa. Coronavirus Disease COVID-19 outbreak. [Online] Avaliable: https://www.afro.who.int/news/second -covid-19-case-confirmed-africa (April $25,2020)$

WHO. (2020d). WHO West African Region: Information, Health Emergency Assessment. [Online] Avaliable: https://apps.who.int/iris/bitstream/handle/10665/331655/SITREP_COVID -19_WHOAFRO_20200401-eng.pdf (May 2, 2020)

WHO. (2020e). Coronavirus disease 2019 (COVID-19): Situation Report - 51. World Health Organization, Geneva, Switzerland. [Online] Avaliable: https://www.who.int/docs/defaultsource/coronaviruse/situation-reports/20200311 -sitrep-51-covid-19.pdf?sfvrsn=1ba62e57_10 (March 13, 2020)

WMHC. (2020). Wuhan, Municipal Health and Health Commission's Briefing on the Current Pneumonia Epidemic Situation in Our City. [Online] Avaliable:

http://wjw.wuhan.gov.cn/front/web/showDetail/2019123108989 (April 18, 2020) 
Worldometer. (2020). COVID-19 Coronavirus Pandemic: Reported Cases and Deaths by Country. Territory, or Conveyance, Ghana. [Online] Avaliable: https://www.worldometers.info/coronavirus/ country/ghana/ (August 7, 2020)

\section{Tables}

Table 1: Sociodemographic attributes of respondents.

\begin{tabular}{|c|c|c|}
\hline Socio-demographic characteristic & $\begin{array}{c}\text { Frequency } \\
(\mathrm{n})\end{array}$ & $\begin{array}{c}\text { Percentage } \\
(\%)\end{array}$ \\
\hline \multicolumn{3}{|l|}{ Age groups (Years) } \\
\hline$<15$ & 0 & 0.0 \\
\hline $15-24$ & 238 & 47.3 \\
\hline $25-54$ & 241 & 47.9 \\
\hline $55+$ & 24 & 4.8 \\
\hline Total & 503 & 100.0 \\
\hline \multicolumn{3}{|l|}{ Sex } \\
\hline Male & 350 & 69.6 \\
\hline Female & 153 & 30.4 \\
\hline Total & 503 & 100.0 \\
\hline \multicolumn{3}{|l|}{ Educational Background } \\
\hline Primary education & 5 & 1.0 \\
\hline Middle/JSS/JHS & 25 & 5.0 \\
\hline Secondary education & 98 & 19.5 \\
\hline Tertiary & 375 & 74.5 \\
\hline Total & 503 & 100.0 \\
\hline \multicolumn{3}{|l|}{ Employment status } \\
\hline Students & 280 & 55.7 \\
\hline Formal Sector employee & 162 & 32.2 \\
\hline Informal Sector employee & 36 & 7.1 \\
\hline Unemployed & 25 & 5.0 \\
\hline Total & 503 & 100.0 \\
\hline \multicolumn{3}{|l|}{ Religion } \\
\hline Muslims & 92 & 18.3 \\
\hline Christians & 392 & 77.9 \\
\hline Traditionalists & 9 & 1.8 \\
\hline Non-religious & 10 & 2.0 \\
\hline Total & 503 & 100.0 \\
\hline \multicolumn{3}{|l|}{ Marital Status } \\
\hline Never married/single & 348 & 69.2 \\
\hline Married/In Union & 140 & 27.8 \\
\hline Widowed & 9 & 1.8 \\
\hline Divorced & 6 & 1.2 \\
\hline Total & 503 & 100.0 \\
\hline
\end{tabular}

Source: Survey Data, (2020)

Table 2: Sources, providers, and types of information on COVID-19, often heard 


\begin{tabular}{lccc}
\hline Source, Provider and type of IEC ${ }^{*}$ on COVID-19 & Frequency & & Percentage \\
& $(\mathrm{n})$ & $(\%)$ \\
\hline Source of IEC ${ }^{*}$ on COVID-19 for respondents & & \\
\hline Social Media & 334 & 66.4 \\
\hline Television (TV) channel & 128 & 25.4 \\
\hline Radio & 35 & 7.0 \\
\hline Family/Friends & 6 & 1.2 \\
\hline Newspaper & 0 & 0.0 \\
\hline Total & 503 & 100.0 \\
\hline Providers of IEC ${ }^{*}$ on COVID-19 & & \\
Health professionals & 392 & 77.9 \\
\hline Non-health professionals & 111 & 22.1 \\
\hline Total & 503 & 100.0 \\
\hline Types of IEC ${ }^{*}$ messages on COVID-19 often heard & & \\
Prevention & 301 & 59.8 \\
\hline Risk Factors & 86 & 17.1 \\
\hline Treatment methods & 20 & 4.0 \\
\hline Nature of the virus & 9 & 1.8 \\
\hline Mode of transmission of the virus & 87 & 17.3 \\
\hline Total & 503 & 100.0 \\
\hline
\end{tabular}

* NB: IEC means Information, Education and Communication.

Source: Survey Data, (2020)

Table 3: Most concerned with impact and willingness to accept treated patients

\begin{tabular}{lccc}
\hline Impact and willingness variables & Frequency & & Percentage \\
COVID-19 impact of most concern to respondents & $(\mathrm{n})$ & & \\
& & \\
\hline Global infections & 108 & 21.5 \\
\hline Local infections & 106 & 21.1 \\
\hline Personal infections & 141 & 28.0 \\
\hline Family/friends infections & 62 & 12.3 \\
\hline Restrictions (Movement, social/religious gatherings) & 41 & 8.1 \\
\hline Economic & 35 & 7.0 \\
\hline Travel restrictions & 10 & 2.0 \\
\hline Total & $\mathbf{5 0 3}$ & $\mathbf{1 0 0 . 0}$ \\
\hline Willingness to accept treated COVID-19 patients back & & \\
& & \\
Highly willing & 251 & 49.9 \\
\hline Willing & 172 & 34.2 \\
\hline Less willing & 80 & 15.9 \\
\hline Total & $\mathbf{5 0 3}$ & $\mathbf{1 0 0 . 0}$ \\
\hline
\end{tabular}

Source: Survey Data, (2020)

Table 4: Perceived ability to observe the infection prevention protocols for COVID-19 


\begin{tabular}{lccccc}
\hline Recommended Infection prevention protocol & Highly Able & Able & Less Able & Not Able & Total \\
\cline { 2 - 6 } & $\mathrm{n}(\%)$ & $\mathrm{n}(\%)$ & $\mathrm{n}(\%)$ & $\mathrm{n}(\%)$ & $\mathrm{n}(\%)$ \\
\hline Frequent hand washing with soap under running water & $141(28.0)$ & $276(54.9)$ & $77(15.3)$ & $9(1.8)$ & $\mathbf{5 0 3 ( 1 0 0 . 0 )}$ \\
\hline Frequent use of alcohol-based hand sanitizing gel & $117(23.3)$ & $226(44.9)$ & $144(28.6)$ & $16(3.2)$ & $\mathbf{5 0 3 ( 1 0 0 . 0 )}$ \\
& & & & & \\
\hline Observing social/physical distance & $117(23.3)$ & $205(40.7)$ & $167(33.2)$ & $14(2.8)$ & $\mathbf{5 0 3 ( 1 0 0 . 0 )}$ \\
\hline Avoidance of touching of face (eyes, nose, and mouth) & $71(14.1)$ & $157(31.2)$ & $247(49.1)$ & $28(5.6)$ & $\mathbf{5 0 3 ( 1 0 0 . 0 )}$ \\
\hline Observing respiratory hygiene (cough etiquette) & $92(18.3)$ & $187(37.2)$ & $208(41.3)$ & $16(3.2)$ & $\mathbf{5 0 3 ( 1 0 0 . 0 )}$ \\
\hline Seeking early medical care on suspicion of infection & $106(21.1)$ & $200(39.7)$ & $174(34.6)$ & $23(4.6)$ & $\mathbf{5 0 3 ( 1 0 0 . 0 )}$ \\
\hline Staying informed and adhering to advice on COVID-19 & $105(20.9)$ & $202(40.1)$ & $185(36.8)$ & $11(2.2)$ & $\mathbf{5 0 3 ( 1 0 0 . 0 )}$ \\
\hline
\end{tabular}

Source: Survey Data, (2020)

\section{Figures}

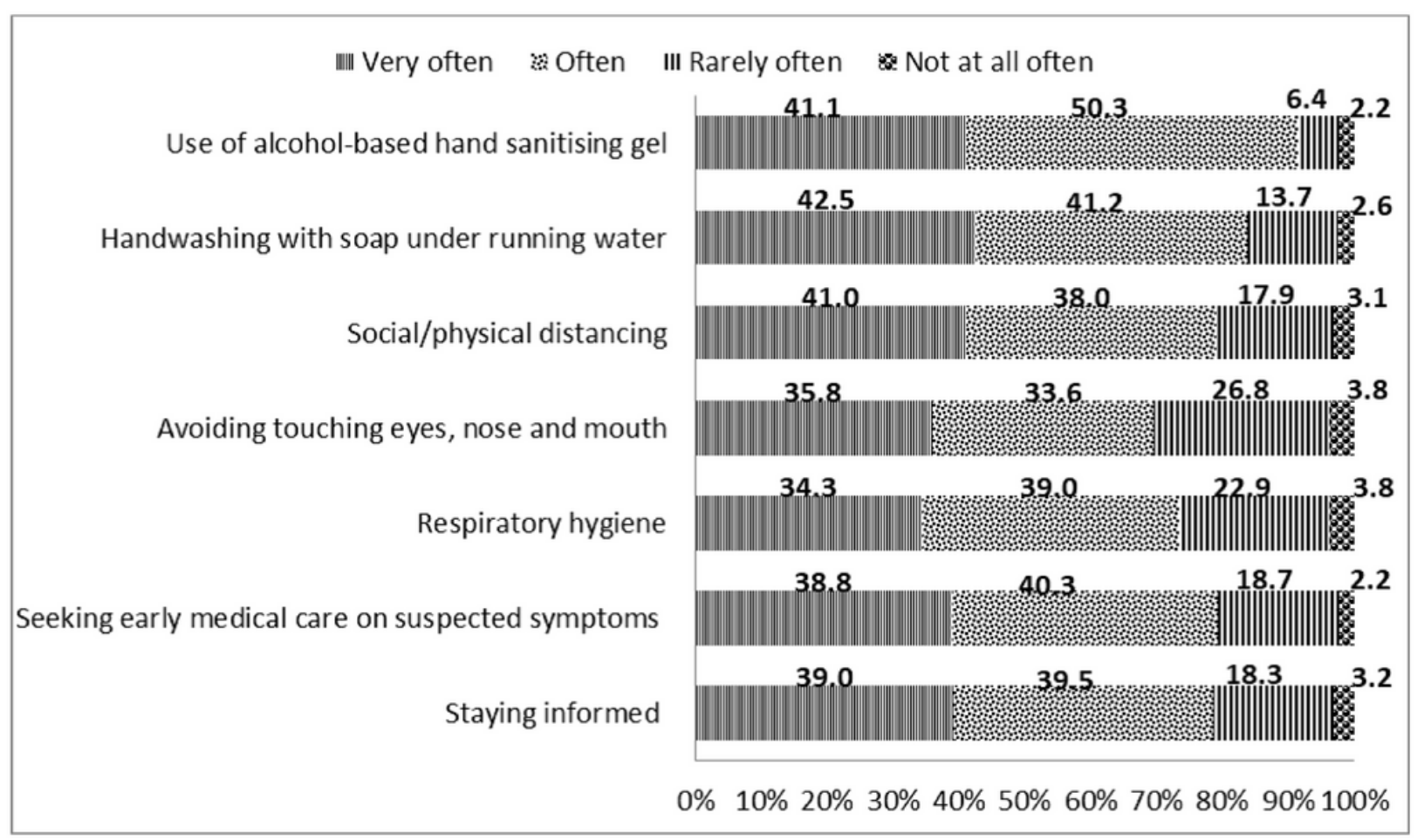

Source: Survey Data, (2020)

\section{Figure 1}

Frequencies and types of IECs heard/read on COVID-19 infection prevention 


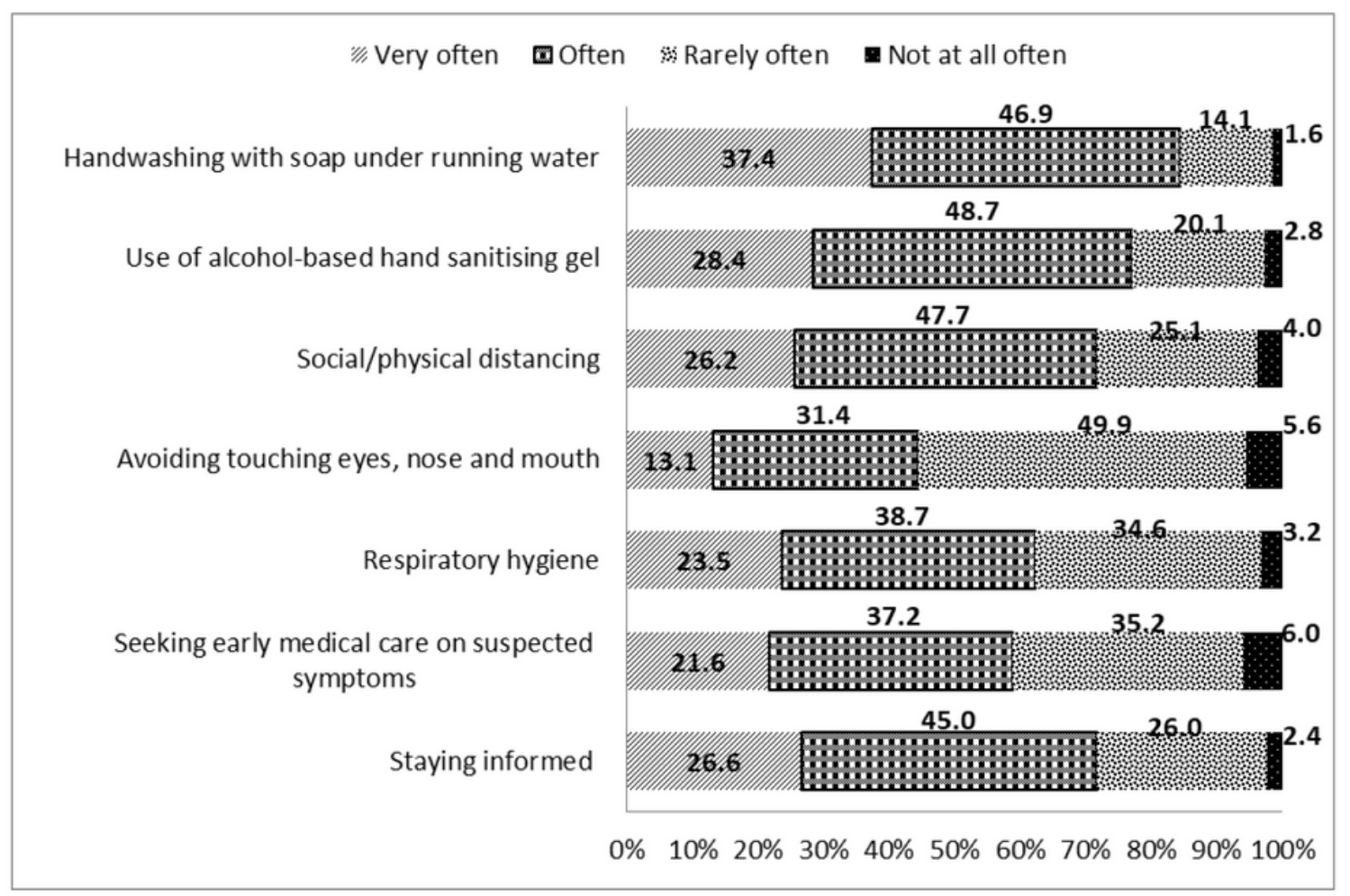

Source: Survey Data, (2020)

\section{Figure 2}

Attitude towards adherence to COVID-19 infections prevention protocols 


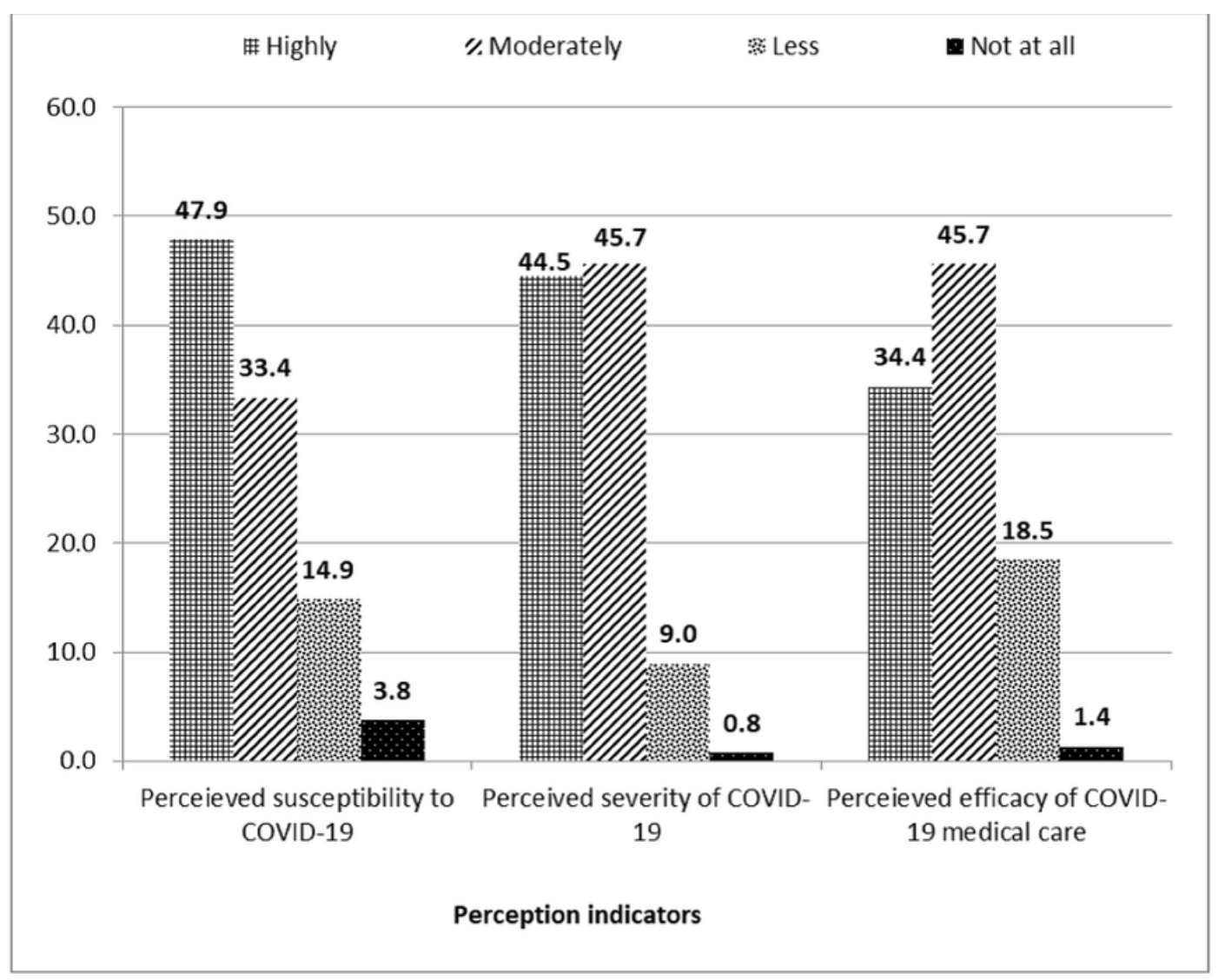

Source: Survey Data, (2020)

\section{Figure 3}

Perceived susceptibility, severity, and efficacy of current medical care, for COVID-19 